\title{
Utilizing the adjuvant properties of CD1d-dependent NK T cells in T cell-mediated immunotherapy
}

\author{
Jonathan D. Silk, ${ }^{1}$ lan F. Hermans, ${ }^{1}$ Uzi Gileadi, ${ }^{1}$ Tsung Wen Chong, ${ }^{1}$ Dawn Shepherd, ${ }^{1}$ \\ Mariolina Salio, ${ }^{1}$ Bini Mathew, ${ }^{2}$ Richard R. Schmidt, ${ }^{2}$ Sarah Jane Lunt, ${ }^{3}$ Kaye J. Williams, ${ }^{3}$ \\ Ian J. Stratford, ${ }^{3}$ Adrian L. Harris, ${ }^{4}$ and Vincenzo Cerundolo ${ }^{1}$
}

${ }^{1}$ Tumour Immunology Unit, Weatherall Institute of Molecular Medicine, University of Oxford, John Radcliffe Hospital, Oxford, United Kingdom. ${ }^{2}$ Department of Chemistry, University of Konstanz, Konstanz, Germany. ${ }^{3}$ School of Pharmacy and Pharmaceutical Sciences, The University of Manchester, Manchester, United Kingdom. ${ }^{4}$ Molecular Oncology Laboratory, Weatherall Institute of Molecular Medicine, University of Oxford, John Radcliffe Hospital, Oxford, United Kingdom.

Activation of invariant CD1d-dependent NK T cells ( $i$ NKT cells) in vivo through administration of the glycolipid ligand $\alpha$-galactosylceramide ( $\alpha$-GalCer) or the sphingosine-truncated $\alpha$-GalCer analog OCH leads to CD40 signaling as well as the release of soluble molecules including type 1 and $\gamma$ interferons that contribute to DC maturation. This process enhances $\mathrm{T}$ cell immunity to antigens presented by the $\mathrm{DC}$. The adjuvant activity is further amplified if APCs are stimulated through Toll-like receptor 4, suggesting that $i$ NKT cell signals can amplify maturation induced by microbial stimuli. The adjuvant activity of $\alpha$-GalCer enhances both priming and boosting of $\mathrm{CD8}^{+} \mathrm{T}$ cells to coadministered peptide or protein antigens, including a peptide encoding the clinically relevant, HLA-A2-restricted epitope of the human tumor antigen NY-ESO-1. Importantly, $\alpha-G a l C e r$ was used to induce $\mathrm{CD8}^{+} \mathrm{T}$ cells to antigens delivered orally, despite the fact that this route of administration is normally associated with blunted responses. Only $T$ cell responses induced in the presence of $i$ NKT cell stimulation, whether by the i.v. or oral route, were capable of eradicating established tumors. Together these data highlight the therapeutic potential of $i$ NKT cell ligands in vaccination strategies, particularly "heterologous prime-boost" strategies against tumors, and provide evidence that $i$ NKT cell stimulation may be exploited in the development of oral vaccines.

\section{Introduction}

Advances in recombinant DNA technology have permitted the design of "subunit" vaccines directed at protein targets, providing immunotherapy with a degree of specificity that was not possible using traditional vaccines based on live attenuated pathogens, whole inactivated organisms, or inactivated toxins. Subunit vaccines may also have the advantage of reduced risk associated with handling and administration and could be more commercially viable due to the simpler manufacturing processes involved. Such specificity has also provided a platform for the design of effective $\mathrm{T}$ cell therapy against complex disease conditions such as cancer. The recent identification of tumor-associated antigens has permitted the generation of subunit vaccines aimed at eliciting cytotoxic T lymphocytes (CTLs) with the capacity specifically to eradicate tumor tissue. The cancer-testis (CT) antigens are particularly promising targets for such therapy (1), as these proteins are expressed in tumor tissue but not in normal adult somatic tissue. This distribution is likely to reduce the risk of autoimmunity associated with therapy. Of the known CT antigens, one of the most promising is NY-ESO- 1 , which is broadly expressed in a variety of human tumors (2).

Nonstandard abbreviations used: $\alpha$-GalCer, $\alpha$-galactosylceramide; CT, cancer-testis; $i$ NKT cells, invariant CD1d-dependent NK T cells; LSEC, liver sinusoidal endothelial cell; MPL, monophosphoryl lipid A; NKT cell, NK T cell; OCH, sphingosine-truncated $\alpha$-GalCer analog; TLR, Toll-like receptor; vacc-OVA, vaccinia virus encoding the fulllength OVA gene.

Conflict of interest: The authors have declared that no conflict of interest exists.

Citation for this article: J. Clin. Invest. 114:1800-1811 (2004).

doi:10.1172/JCI200422046
There has been increasing interest in so-called "heterologous prime-boost" vaccination protocols, in which patients are immunized consecutively with different recombinant vectors encoding the same antigen. This strategy permits restimulation of antigen-specific $\mathrm{T}$ cells without the confounding effect of neutralizing responses directed at the vector itself (3). Studies have highlighted the potential of DNA and live viral vectors in this context; in those studies, recombinant DNA constructs were used to prime $T$ cells, and recombinant vaccinia viral vectors were used to "boost" the induced responses (4-7). However, the evidence that plasmid DNA is as strongly immunogenic in humans as it is in nonhuman primates and rodents is rather limited $(5,8,9)$. A more powerful priming strategy is required to exploit heterologous prime-boost protocols in the clinic. Injection of recombinant proteins or peptides may prove to be the simplest approach, as these reagents are devoid of vector sequences. However, in the absence of adjuvants, proteins and peptides are also poorly immunogenic. Immunogenicity may be improved if proteins or peptides are loaded onto immunostimulatory cells, such as DCs $(10,11)$, although clinical studies so far indicate modest increases that are outweighed by increased complexity in vaccine preparation (12). It is becoming apparent, therefore, that primeboost protocols may benefit from the identification and development of immunological adjuvants that improve the efficacy of protein- or peptide-based vaccines.

Many substances with adjuvant activity, particularly those of microbial origin, have been shown to enhance DC function in situ via stimulation through pattern-recognition receptors, of which Toll-like receptors (TLRs) are prime examples (13). Activated T cells 
A
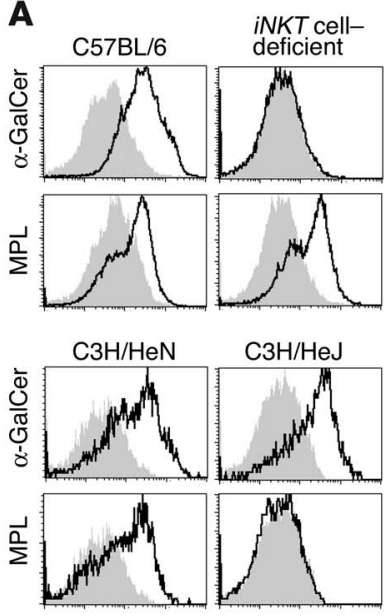

iNKT cell-

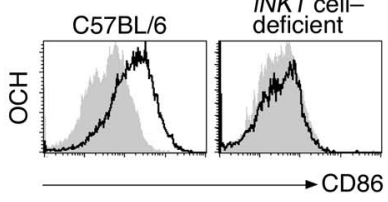

B $\pm \alpha$-GalCer in vitro $\quad$ C

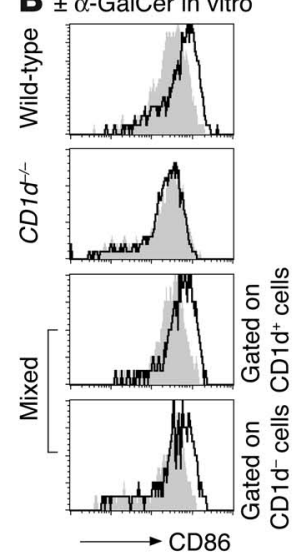

C

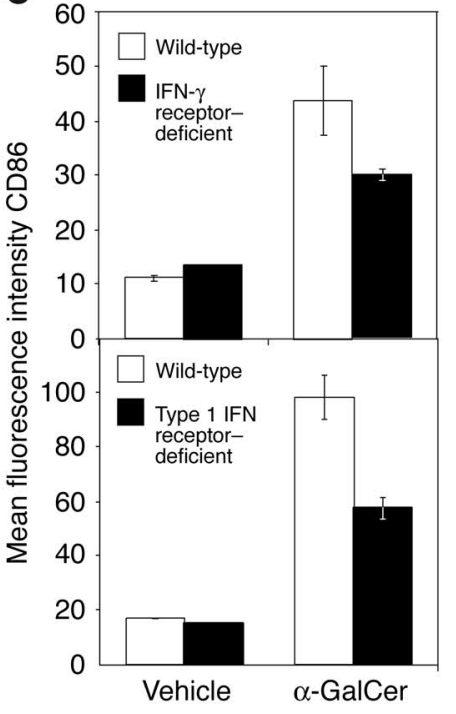

D

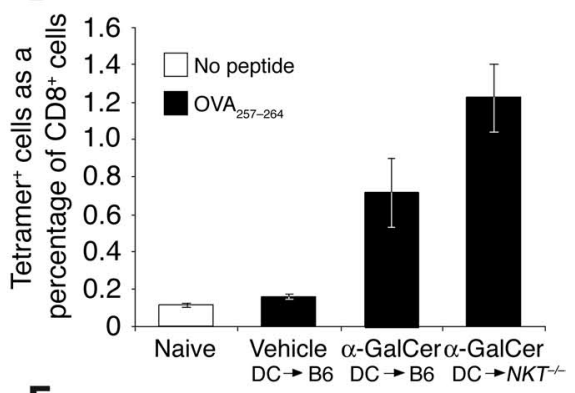

$\mathbf{E}$

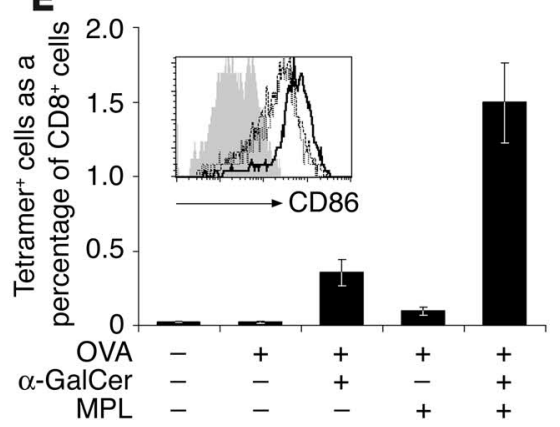

Figure 1

Injection of $i$ NKT cell ligands induces maturation of splenic DCs, increasing their immunostimulatory capacity. (A) Animals were treated i.v. with $1 \mu \mathrm{g}$ of $\alpha$-GalCer or its analog OCH, or with $25 \mu \mathrm{g}$ of the TLR4 ligand MPL, and surface expression of CD86 was assessed on splenic CD11 $\mathrm{C}^{+}$ cells 24 hours later relative to that of cells from vehicle-treated animals (gray filled histograms). C3H/HeJ mice, which have a mutation in TLR4, or iNKT cell-deficient mice were used along with their respective controls (C3H/HeN and C57BL/6). (B) Surface expression of CD86 on CD11C ${ }^{+}$ cells was assessed on splenocytes from wild-type C57BL/6 or CD1d $d^{-/-}$mice or a mixture of splenocytes from both (Mixed), stimulated in vitro with (thick solid lines) or without $\alpha$-GalCer (gray filled histograms) for 16 hours. (C) Mean fluorescence intensity of CD86 ( \pm SE) assessed on CD11c ${ }^{+}$ cells from the spleens of IFN- $\gamma$ receptor-deficient and type I IFN receptor-deficient animals that had received $\alpha$-GalCer or vehicle 16 hours previously. (D) The immunostimulatory capacity of splenic CD11c cells from $\alpha-$ GalCer- or vehicle-treated C57BL/6 (B6) animals was assessed by loading with $\mathrm{OVA}_{257-264}$ peptide ex vivo and transferring antigen-loaded cells into naive C57BL/6 and $i$ NKT cell-deficient recipients $(n=5)($ arrows indicate direction of DC transfer). $\mathrm{OVA}_{257-264}-$ specific $\mathrm{CD} 8^{+} \mathrm{T}$ cell responses in recipient animals were measured in the blood by FACS analysis using $\mathrm{H}-2 \mathrm{~K}^{\mathrm{b}} / \mathrm{OVA}_{257-264}$ tetramers 7 days after transfer. Mean proportions of tetramer+ cells as a percentage of CD8 ${ }^{+}$cells $( \pm \mathrm{SE})$ are shown. (E) Inset shows expression of CD86 on splenic CD11 $\mathrm{C}^{+}$cells from C57BL/6 mice injected with vehicle (gray filled histogram), $\alpha$-GalCer (thick dashed line), MPL (thin dashed line), or $\alpha$-GalCer plus MPL (thick solid line). Graph shows $\mathrm{OVA}_{257-264}-$ specific CD8 ${ }^{+} \mathrm{T}$ cell responses enumerated in the blood by FACS analysis 7 days after administration of $400 \mu \mathrm{g}$ OVA with various combinations of vehicle, $\alpha$-GalCer, or MPL.

themselves can also activate DCs, and in this context, monospecific $\mathrm{T}$ cell subpopulations among $\gamma / \delta$ T cells and NK T cells (NKT cells) can be potent sources of stimulatory signals for DCs $(14,15)$. Invariant CD1d-dependent NKT cells (iNKT cells) expressing an invariant T cell receptor (TCR) $\alpha$ chain encoded by V $\alpha 14-J \alpha 18$ gene segments in mice or $V \alpha 24-J \alpha 18$ in humans are found at high frequency in spleen, bone marrow, thymus, and liver $(16,17)$. Although the natural ligand for such invariant TCR-expressing cells has not been defined, the marine sponge-derived glycolipid $\alpha$-galactosylceramide ( $\alpha$-GalCer) has been shown to specifically activate $i$ NKT cells (18). We and others have shown recently that activating iNKT cells with $\alpha$-GalCer can have powerful adjuvant activity, promoting the enhanced development of both $\mathrm{CD}^{+}$and $\mathrm{CD}^{+} \mathrm{T}$ cell populations specific for exogenously delivered protein antigens $(19,20)$. Accumulating data, including work presented here, suggest that increased $T$ cell responses in the presence of $i$ KKT cell stimulation can be directly attributed to enhanced function of APCs such as DCs at the time of T cell priming. A recent study by Fujii et al. (21) showed that DC maturation occurs in response to $i$ NKT cell stimulation via the release of TNF- $\alpha$ in concert with IFN- $\gamma$. In support of that finding, we show here that once activated, $i \mathrm{NKT}$ cells promote the provision of soluble factors, including both type I and $\gamma$ IFNs, that can act in trans to mature both DCs and B cells. The adjuvant effect of $i$ NKT cell stimulation is significantly enhanced if DCs are also stimulated through TLR4, suggesting that signals transmitted to DCs by $i$ NKT cells can amplify the effect of pathogen-induced signals. Whereas maturation is mediated by soluble factors, our previous studies and those of Fujii et al. (21) indicate that enhancement of T cell responses by $i$ NKT cells is critically dependent on CD40 signaling. As has been reported for the cross-talk between $\mathrm{CD}^{+} \mathrm{T}$ cells and DCs (22), independent transand cis-acting interactions may be required to enable $i$ NKT cells to promote conventional $\mathrm{T}$ cell-mediated immunity. We report here an extensive analysis of the utility of $i$ NKT cell stimulation in the development of vaccines, particularly in the context of $\mathrm{CD}^{+} \mathrm{T}$ cell generation by heterologous prime-boost protocols. The adjuvant activity of $i \mathrm{NKT}$ cell stimulation enhanced both the priming and boosting of $\mathrm{CD}^{+} \mathrm{T}$ cell responses to subunit vaccines incorporating peptide or protein antigens. Among the antigens assessed was a clinically relevant, HLA-A2-restricted epitope of the human tumor antigen NY-ESO-1. Of particular note was the finding that the adjuvant effect of $i$ NKT cell stimulation was exerted after oral administration of vaccine and $i$ NKT cell ligand, a route considered to be most 
A
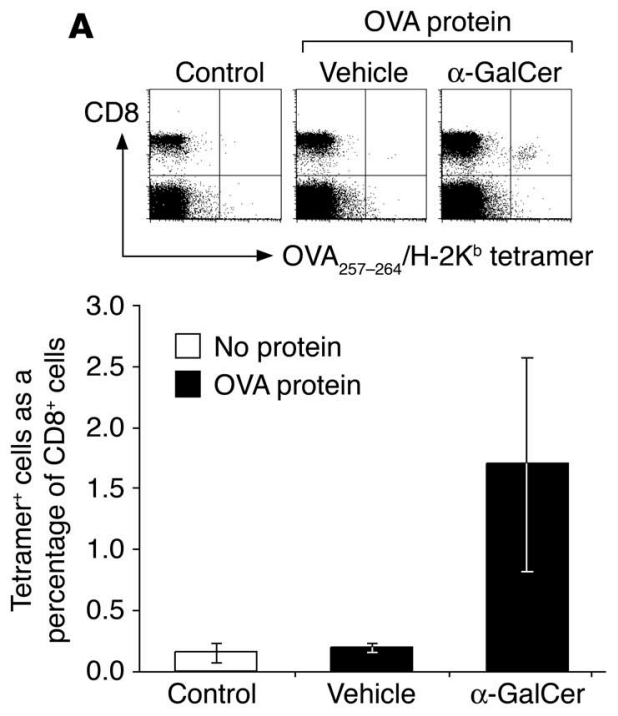

B
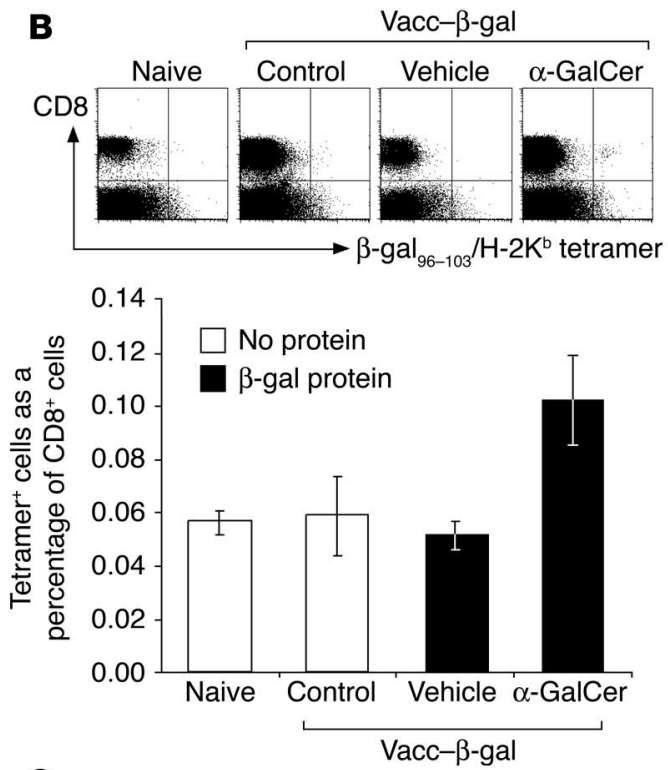

C

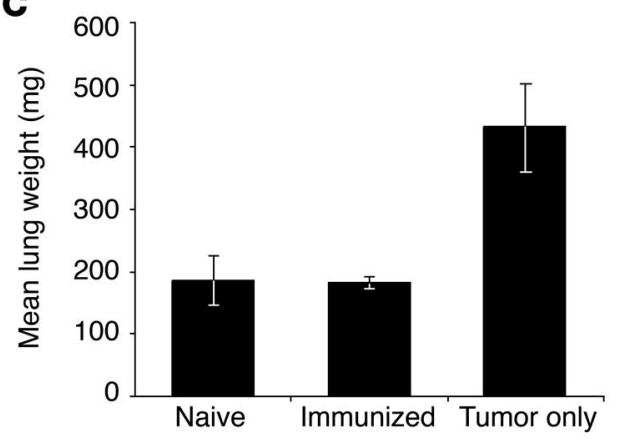

Figure 2

$\mathrm{CD}^{+} \mathrm{T}$ cell responses induced by i.v. injection of various model antigens can be enhanced by coadministration of $\alpha$-GalCer. (A) Whole OVA (400 $\mu \mathrm{g} /$ mouse) was injected i.v. into C57BL/6 mice together with either $\alpha$-GalCer $\left(1 \mu \mathrm{g} /\right.$ mouse) or vehicle. Induction of $\mathrm{OVA}_{257-264}-$ specific $C D 8^{+} \mathrm{T}$ cell responses was assessed in the blood by FACS analysis 7 days later. FACS profiles of naive animals (Control) and those receiving OVA with $\alpha$-GalCer or with vehicle are shown. (B) Whole $\beta$-gal protein $(400 \mu \mathrm{g} /$ mouse) was injected together with either $\alpha$-GalCer or vehicle, and then all recipient animals were injected with vacc- $\beta$-gal $\left(5 \times 10^{5} \mathrm{PFU} /\right.$ mouse $) 7$ days later in order to expose weakly primed responses. Induction of $\mathrm{CD}^{+} \mathrm{T}$ cell responses specific for $\beta$-gal ${ }_{96-103}$ was assessed in the blood 7 days after vaccinia treatment. (C) Animals immunized with $\beta$-gal protein together with $\alpha$-GalCer, followed by vacc- $\beta$-gal, were challenged 7 days later with the $\beta$-gal-expressing tumor Z16 injected i.v. Growth of lung metastases was compared with growth observed in unimmunized animals (Tumor only).

promising in terms of likely patient usage. Furthermore, responses induced in the presence of $i$ NKT cell stimulation, by either the i.v. or the oral route, were capable of inducing CTLs endowed with antitumor activity. These findings suggest that $i$ NKT cell ligands could be valuable compounds for use in $\mathrm{T}$ cell vaccines for the treatment of cancer and infectious agents (19).

\section{Results}

Induction of iNKT cell activity with specific agonists serves to induce and/or enhance maturation of DCs. Injection of $\alpha$-GalCer i.v. into C57BL/ 6 mice leads to the specific activation of $i$ NKT cells, which correlates with significant increases in serum levels of the cytokines IL-4, IL-12, and IFN- $\gamma$ (23). We and others have shown previously that injection of $\alpha$-GalCer also results in the maturation of DCs, as defined by increased expression of the costimulatory molecules CD80 and CD86, and MHC molecules, on CD11 $\mathrm{c}^{+}$cells isolated upregulation of CD86 to levels above those seen in vehicle-treated cultures. No increase in CD86 expression was seen in splenocyte cultures from $C D 1 d^{-/-}$animals. Interestingly, when $\alpha$-GalCer was added to cultures containing both $C D 1 \mathrm{~d}^{+}$and $C D 1 \mathrm{~d}^{-}$splenocytes, enhanced upregulation of CD86 was observed on all CD11 $\mathrm{c}^{+}$cells regardless of CD1d expression. These data indicate that activation of $i$ NKT cells can enhance DC maturation processes and the factor(s) inducing enhancement can act in trans, indicative of soluble mediators. Consistent with the latter possibility, further experiments established that upregulation of CD86 on both DCs and B cells could be triggered across a transwell (Supplemental Figure 1; supplemental material available at http://www.jci.org/ cgi/content/full/114/12/1800/DC1).

Induction of DC maturation was also induced by the sphingosine-truncated $\alpha$-GalCer analog OCH (Figure 1A), an $i$ NKT cell ligand, which induces significantly less IFN- $\gamma$ (27). Taken together 
A
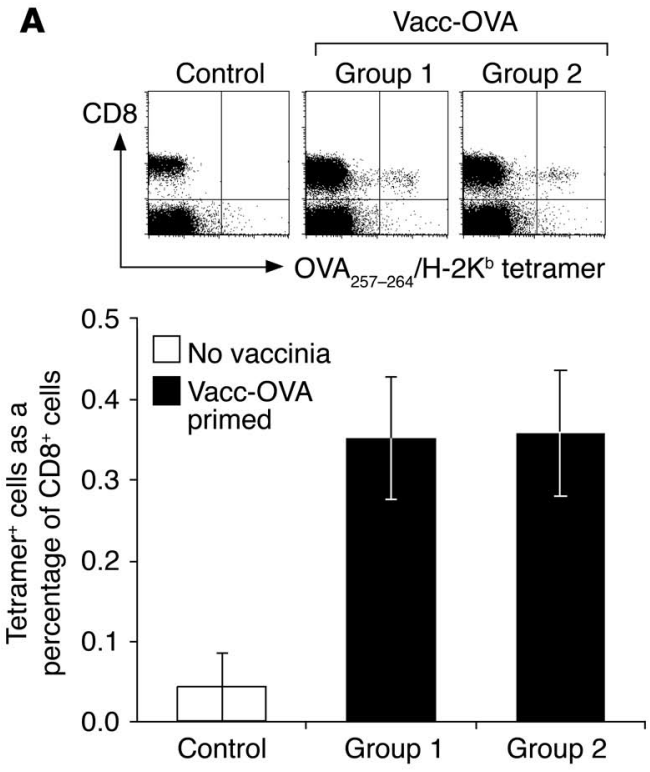

B
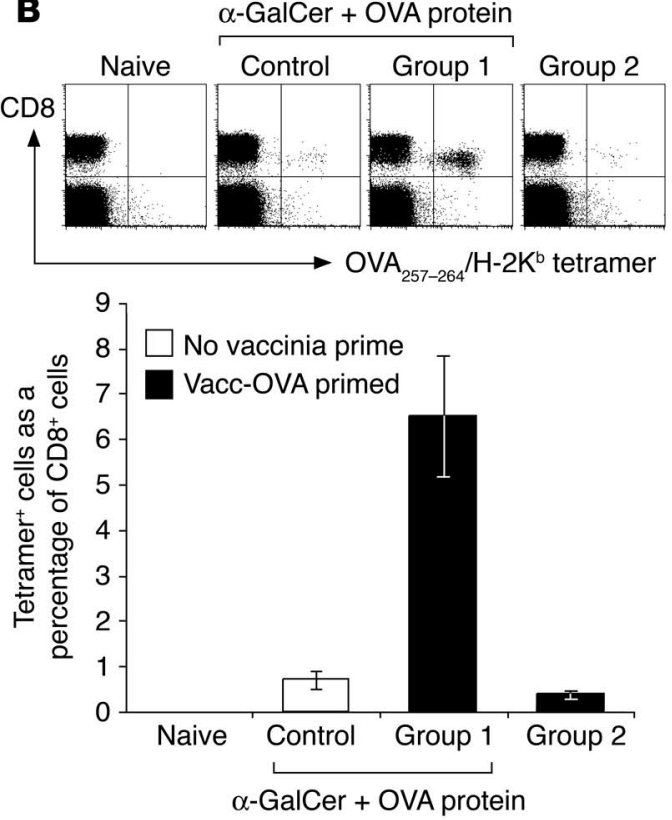

Figure 3

Administration of protein and $\alpha$-GalCer can effectively restimulate CD8+ $T$ cell responses in immune animals. (A) OVA $257-264^{-s p e c i f i c ~ C D 8+~} \mathrm{~T}$ cell responses were assessed in animals primed by i.v. injection of vacc-OVA and then divided into two groups with equivalent responses. (B) Responses in one immune group (Group 1) were then restimulated by treatment with OVA and $\alpha$-GalCer. Responses induced 7 days after restimulation are presented together with those observed in control animals that received OVA with $\alpha$-GalCer treatment only, those that received the vaccinia prime only (Group 2 ), and a naive group.

with the observations that $\mathrm{OCH}$ can act as an adjuvant for $\mathrm{CD}^{+}$ $\mathrm{T}$ cell responses (19) and that $\alpha$-GalCer can induce DC maturation and enhanced $\mathrm{T}$ cell responses in IFN- $\gamma$ receptor-deficient animals (19), this evidence would suggest that IFN- $\gamma$ is not essential for $i$ NKT cell-mediated adjuvant activity. However, a recent report showed that IFN- $\gamma$ was involved in the upregulation of costimulatory molecules on DCs after $\alpha$-GalCer administration, as demonstrated with blocking antibodies to IFN- $\gamma$ (21). In agreement with that study, we found a small but significant reduction in upregulation of CD86 on CD11 $c^{+}$cells from the spleens of IFN- $\gamma$ receptor-deficient animals relative to that of wild-type animals after $\alpha$-GalCer injection (Figure 1C, upper panel). Similarly reduced upregulation of CD86 was seen in type I IFN receptor-deficient animals (Figure 1C, lower panel). Despite the lower levels of costimulatory molecules, $\mathrm{T}$ cell responses were enhanced by $\alpha$-GalCer treatment in both of these receptor knockout strains, as assessed by in vivo and in vitro analysis of CD8 responses to soluble antigens (ref. 19 and data not shown). We conclude, therefore, that both type 1 and $\gamma$ IFNs are involved in the remodeling of costimulatory molecules in response to $i$ NKT cell activation, but that neither is an essential mediator of the adjuvant activity.

To test the functional consequences of $i$ NKT cell-induced maturation, we loaded $\mathrm{CD} 11 \mathrm{c}^{+}$cells isolated from the spleens of $\alpha$-GalCer-treated animals ex vivo with the MHC class I-binding peptide $\mathrm{OVA}_{257-264}$ (amino acids 257-264 of the OVA protein sequence) and then transferred the cells into naive C $57 \mathrm{BL} / 6$ or $i$ NKT cell-deficient recipients (Figure 1D). Analysis of the blood 7 days later with specific MHC class I/peptide tetramers (OVA $257-264$ / $\left.\mathrm{H}-2 \mathrm{~K}^{\mathrm{b}}\right)$ indicated that there was an induction of specific $\mathrm{CD}^{+} \mathrm{T}$ cell responses in both of the recipient strains, whereas transfer of peptide-loaded CD $11 \mathrm{c}^{+}$cells from untreated donors did not induce immunity. Thus, $i$ NKT cells can enhance the induction of $\mathrm{T}$ cell responses by acting only in the priming phase through their action on the DC rather than through any subsequent involvement to sustain immunity.

In combination, $\alpha-G a l C e r$ and the TLR4 ligand MPL act cooperatively in the induction of DC maturation and T cell priming. It was recently reported that proinflammatory cytokines released by DCs in response to microbial stimuli serve to amplify the activation of $i$ NKT cells (28). Given the evidence presented above that activated $i$ NKT cells can, in turn, enhance DC maturation, we investigated the possibility that microbial signals and $i$ NKT cell-mediated signals can be coordinated to modulate further DC-induced T cell immunity. DC maturation was examined in the spleens of animals treated with the TLR4 ligand MPL together with $\alpha$-GalCer or without $\alpha$-GalCer. Treatment i.v. with MPL or $\alpha$-GalCer alone increased expression of CD86 on DCs, as expected. Significantly, when the two compounds were administered together, expression of CD86 was increased to levels well above those seen after treatment with either compound alone (Figure 1E, inset). Similarly, increased expression of CD86 was seen when MPL was used in conjunction with $\mathrm{OCH}$ (data not shown). When wild-type mice were administered chicken OVA protein together with the different compounds, the combination of $\alpha-G a l C e r$ and MPL acted synergistically to induce expansion of $\mathrm{OVA}_{257-264}-$ specific $\mathrm{CD}^{+} \mathrm{T}$ cell responses measured in the blood using MHC class I/peptide tetramers (Figure 1E). Similar synergy was seen with $\mathrm{OCH}$ and MPL treatment in vivo (data not shown). In addition, synergy was observed when splenocytes isolated from animals treated with the different compounds were used to stimulate $\mathrm{CD}^{+} \mathrm{T}$ cells in 
A
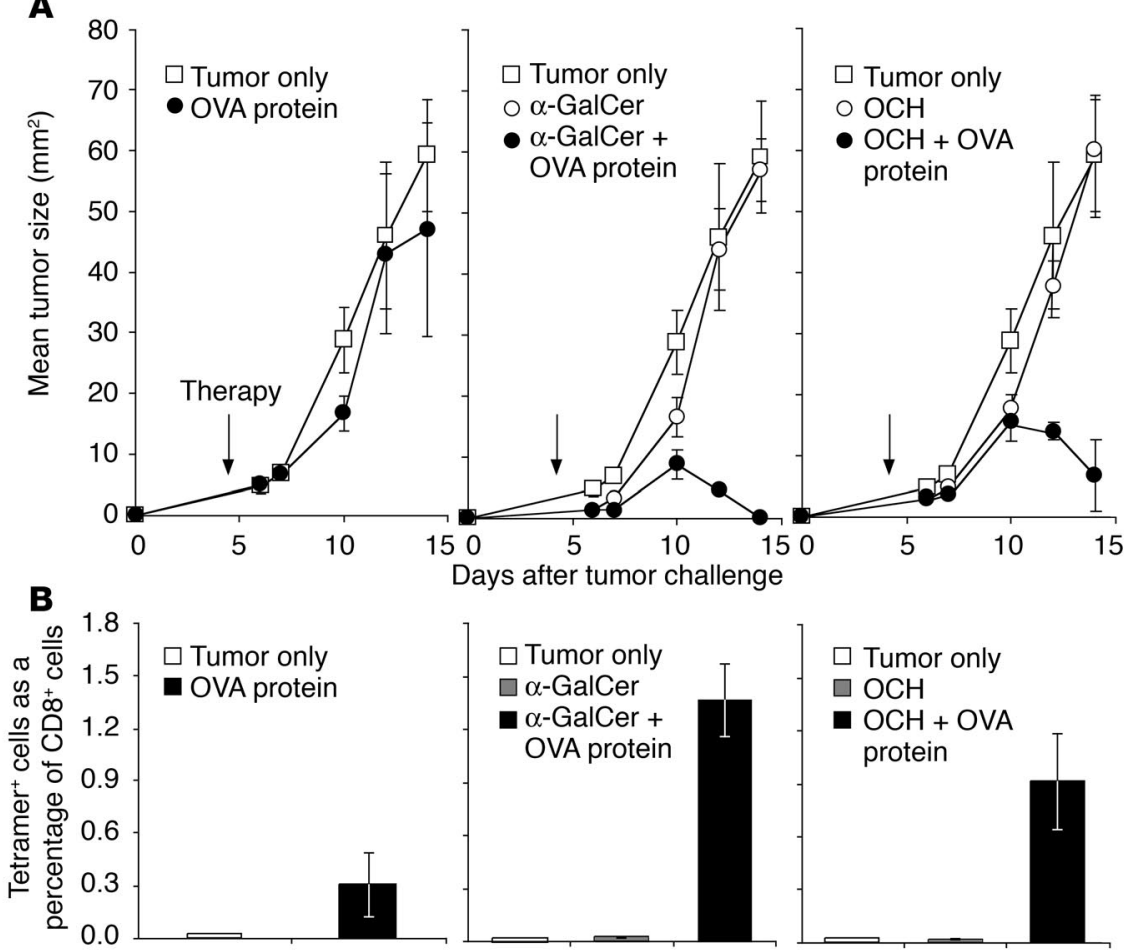

\section{Figure 4}

Coadministration of $i$ NKT cell ligands together with protein provides therapeutic anti-tumor activity. (A) Growth of S.c. implanted E.G7OVA tumors was assessed in animals treated therapeutically 4 days after tumor challenge (as indicated by downward-pointing arrows) by i.v. injection of OVA protein alone, $\alpha$-GalCer or $\mathrm{OCH}$ alone, or a combination of OVA together with either $i$ NKT cell ligand. (B) Induction of $\mathrm{OVA}_{257-264}-$ specific CD8 ${ }^{+} \mathrm{T}$ cell responses was measured in the blood 7 days after therapy described in $\mathbf{A}$ was initiated. vitro (data not shown). We concluded therefore that activated $i$ NKT cells provide signals to APCs that integrate with TLR-mediated signaling of MPL to improve T cell immunity.

The iNKT cell ligands serve as adjuvants for priming and boosting of CTLs and induction of anti-tumor therapy. The adjuvant effect of $i$ NKT cell activation together with OVA administration induces $\mathrm{OVA}_{257-264-}$-specific CD8 ${ }^{+} \mathrm{T}$ cell responses that are highly cytolytic and that can be restimulated with different stimuli (19), including subsequent injection of recombinant vaccinia virus encoding the full-length OVA protein (vacc-OVA) (19). In contrast, responses to OVA in the absence of $i$ NKT cell stimulation are considerably weaker, with less capacity to be restimulated (19). In Figure 2 we compared $i \mathrm{NKT}$ cell-induced $\mathrm{CD}^{+} \mathrm{T}$ cell responses to OVA with those induced to a second model antigen, $\beta$-gal, and showed that immune responses to $\beta$-gal could also be enhanced through the adjuvant activity of $\alpha$-GalCer treatment. In comparison with responses to OVA (Figure 2A), only a small population of specific $\mathrm{CD}^{+} \mathrm{T}$ cells could be detected in the blood, and then only after restimulation of the $\alpha$-GalCer-treated group with vacc- $\beta$-gal (Figure 2B). In the absence of $\alpha$-GalCer, there was no evidence of $\mathrm{CD}^{+} \mathrm{T}$ cell priming, or subsequent boosting with recombinant vaccinia. Nevertheless, the $\beta$-gal-specific responses induced in the presence of $\alpha$-GalCer were sufficient to inhibit lung metastasis of Z16, a $\beta$-gal-expressing derivative of B16.F10 administered by i.v. injection 7 days after a vacc- $\beta$-gal boost (Figure $2 \mathrm{C}$ ). The adjuvant property of $\alpha$-GalCer was therefore apparent with both model antigens, highlighting the potential for $i$ NKT cell ligands in vaccination strategies with whole protein.

Immunotherapy is often dependent upon the restimulation of pre-existing weak responses rather than the induction of de novo immune responses. This is particularly true for the treatment of weakly immunogenic tumors such as melanoma. In this respect, a useful vaccine would be one with potent "boosting" capacity.
In addition, a vaccine that can boost existing responses and is devoid of vector sequences would add considerably to the arsenal of prime-boost reagents. We therefore examined the capacity of protein vaccines administered with $\alpha$-GalCer to boost responses in immune mice. Animals were primed with vacc-OVA, and then assigned to one of two groups with equal overall responses as measured using MHC class I/peptide tetramers (Figure 3A). After 11 days, one of the groups was injected with OVA and $\alpha$-GalCer in order to restimulate existing responses (Figure $3 \mathrm{~B}$ ). This stimulus provided responses that were increased 17-fold over those of vacc-OVA-primed, non-boosted animals and 9-fold over those of control animals primed with protein and $\alpha$-GalCer injection only. Thus, injection with protein and $\alpha$-GalCer was also proven to be a powerful boosting agent.

The adjuvant capacity of $i$ NKT cell ligands $\alpha$-GalCer and OCH was then assessed in the context of protein-based immunotherapy in tumor-bearing mice (Figure 4A). C57BL/6 mice were injected s.c. with E.G7-OVA, a murine thymoma that expresses OVA protein, and therapy was initiated 4 days after challenge, when palpable tumors were apparent at the site of injection. In mice injected with OVA protein alone, the implanted tumors grew progressively without significant resistance despite the existence of a population of $\mathrm{OVA}_{257-264^{-}}$ specific $T$ cells generated by this vaccination procedure (Figure 4B). Mice injected with $\alpha$-GalCer alone, or OCH alone, were unable to eradicate established tumors. In contrast, tumor growth was significantly retarded in mice injected with protein together with either of the two $i$ NKT cell ligands. For both treatments, two phases of growth were observed, with a slightly slower growth of the tumor relative to that of controls up until day 10 , and then rapid regression beyond this point, presumably reflecting the kinetics of $\mathrm{T}$ cell proliferation after vaccination. Regardless of the profile of cytokines induced by these ligands, the adjuvant effect of $i$ NKT cell activation was capable of inducing cytotoxic effector cells with potent anti-tumor activity 
A
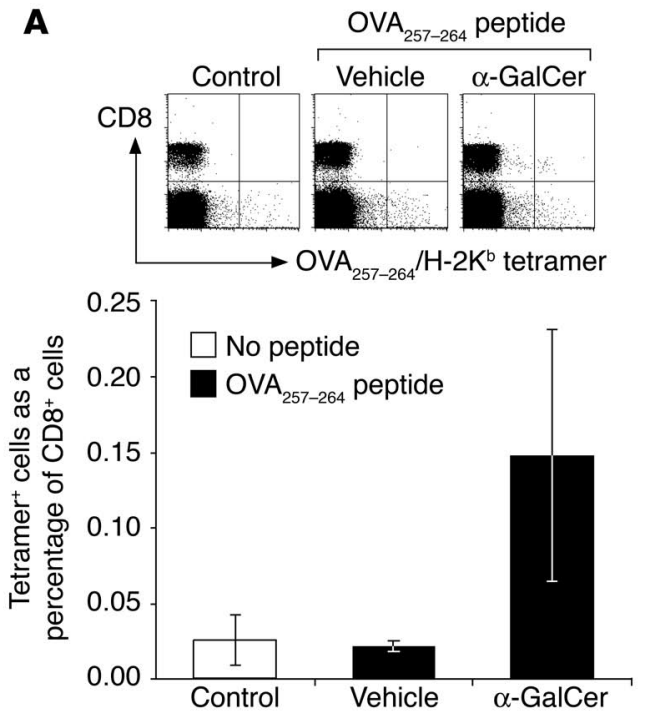

B
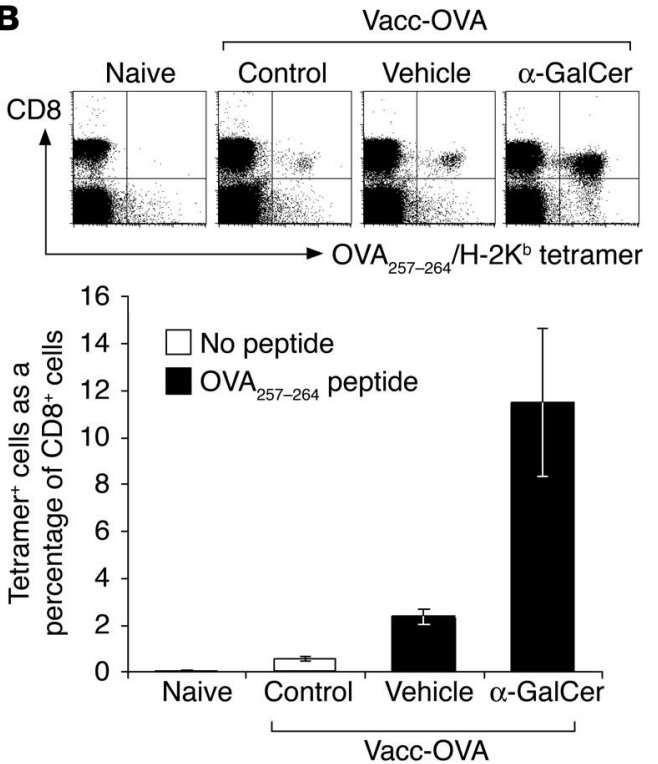

C
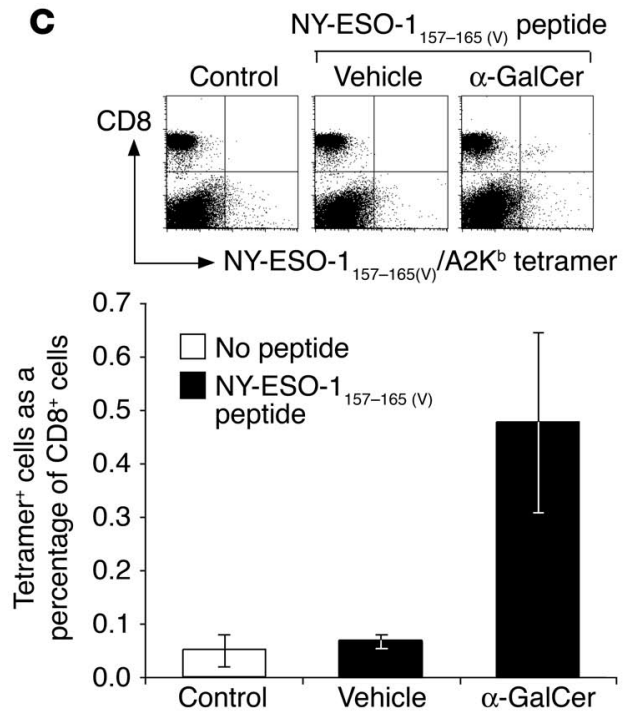

D
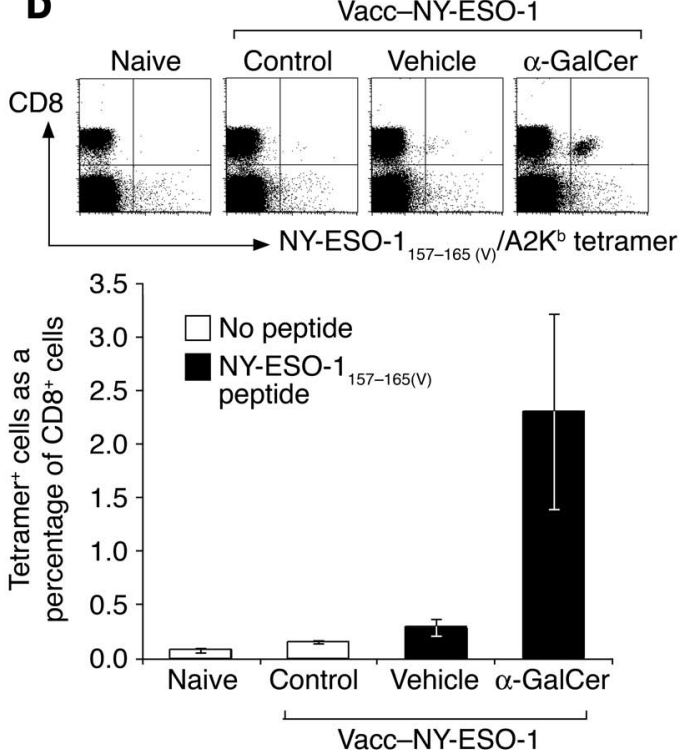

Figure 5

$\mathrm{CD}^{+} \mathrm{T}$ cell responses induced by injection of MHC class l-binding peptides can be enhanced by coadministration of $\alpha$-GalCer. (A) OVA OV7-264 peptide (100 $\mu \mathrm{g} /$ mouse) was injected i.v. together with either $\alpha$-GalCer or vehicle, and induction of specific $\mathrm{CD}^{+} \mathrm{T}$ cell responses was assessed in blood 7 days later. (B) One week after peptide priming, OVA $257-264-$ specific CD8+ $\mathrm{T}$ cell responses were restimulated in vivo by i.v. injection of vacc-OVA $\left(5 \times 10^{5}\right.$ PFU/mouse). Responses induced 7 days after restimulation are presented together with those observed in control animals that received vaccinia alone and those of a naive group. (C) Specific CD8 ${ }^{+} \mathrm{T}$ cell responses were monitored in A2 $\mathrm{K}^{\mathrm{b}}$-transgenic mice after i.p. injection of NYESO-1 $157-165$ (v) peptide together with either $\alpha-G a l-$ Cer or vehicle. (D) The induced responses shown in $\mathbf{C}$ were restimulated by i.v. injection of vaccNY-ESO-1 $\left(1 \times 10^{6} \mathrm{PFU} /\right.$ mouse) 7 days later. that could not be provided by injection of tumor-specific antigen alone. It remains to be established whether provision of cytokines by $i$ NKT cells becomes more important in schedules involving repeated therapy with protein and $i$ NKT cell ligand.

CTL responses to peptide antigens can be enhanced by coadministration of $i N K T$ ligands. The induction of $\mathrm{CD}^{+} \mathrm{T}$ cell responses to administered whole protein is thought to result from antigen uptake and subsequent "cross-presentation" of MHC class I-binding epitopes to naive antigen-specific $\mathrm{CD}^{+} \mathrm{T}$ cells. It is therefore possible that the adjuvant effect of $i$ NKT cell stimulation may arise from increased antigen uptake and processing, as well as increased immunostimulatory capacity of DCs. Were increased antigen processing the only parameter involved in enhancing $\mathrm{CD}^{+} \mathrm{T}$ cell responses, peptide vaccines would not be improved by $i$ NKT cell stimulation, as they are independent of processing. In order to determine whether peptide vaccines can be enhanced by $i$ NKT cell stimulation, we coadministered $\alpha$-GalCer with OVA $_{257-264}$ peptide. The presence of $\mathrm{OVA}_{257-264}$-specific $\mathrm{CD}^{+} \mathrm{T}$ cells was assessed in the blood using MHC class I/peptide tetramers 7 days later (Figure 5A). Injection of peptide in the absence of $\alpha$-GalCer did not induce any detectable response above background. In contrast, coinjection of peptide and $\alpha$-GalCer induced a small $\mathrm{OVA}_{257-264}$-specific $\mathrm{CD}^{+} \mathrm{T}$ cell population in $60 \%$ of vaccinated mice. As our experiments with $\beta$-gal protein have shown (Figure 2 ), weak $\mathrm{T}$ cell responses that cannot be detected with MHC class I/ peptide tetramers after priming are exposed by subsequent boosting with vaccinia virus encoding the antigen of interest. The peptide-primed responses were therefore restimulated with vaccOVA and then evaluated 7 days later. This experiment (Figure 5B) showed that $\alpha$-GalCer treatment enhanced peptide priming. While $\mathrm{OVA}_{257-264-\text { specific }} \mathrm{CD}^{+} \mathrm{T}$ cells were also detectable by tetramer ex vivo in mice injected with peptide in vehicle, responses primed in the presence of $\alpha$-GalCer were significantly higher, such that on average $12 \%$ of $\mathrm{CD}^{+} \mathrm{T}$ cells were specific for the $\mathrm{OVA}_{257-264}$ epitope. This result suggests that the adjuvant effect of $i$ NKT cell stimulation with $\alpha$-GalCer can be independent of antigen processing, indicating that an important effect of $i$ NKT cells on DCs is to enhance their immunostimulatory capacity. Additionally, this 
A
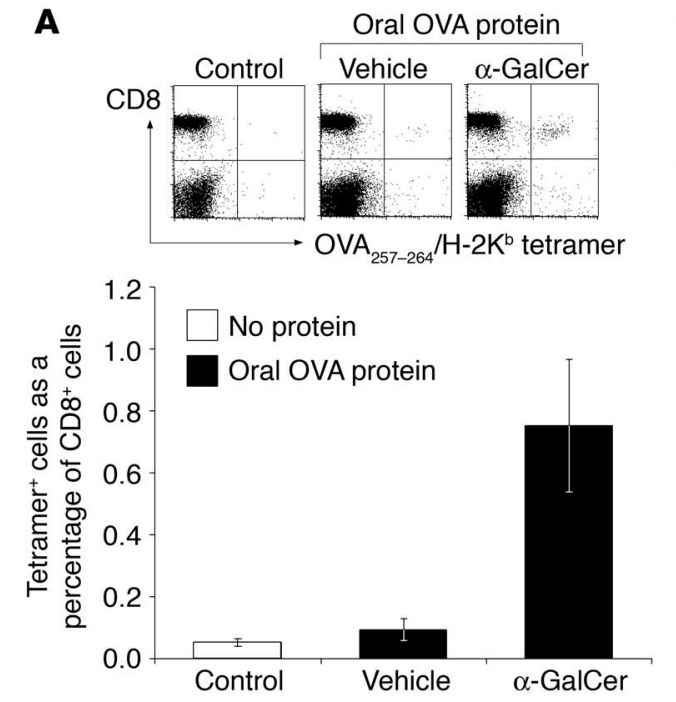

B
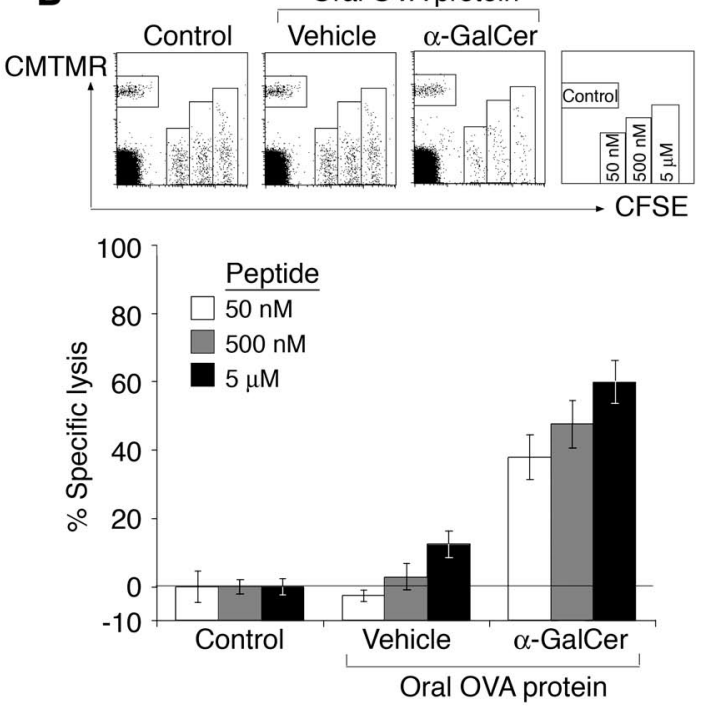

Figure 6

Oral administration of soluble antigen and $\alpha$-GalCer induces functional CTLs. (A) Whole OVA was administered by gavage (30 mg/mouse) together with either $\alpha$-GalCer $\left(8 \mu \mathrm{g} /\right.$ mouse) or vehicle. Induction of $\mathrm{OVA}_{257-264} \mathrm{CD}^{+} \mathrm{T}$ cell responses was assessed in the blood 7 days later. (B) Cytolytic activity of the induced $\mathrm{OVA}_{257-264}-$ specific response was assessed in vivo 11 days after OVA administration against syngeneic splenocytes loaded with titrated doses of $\mathrm{OVA}_{257-264}$ peptide as indicated in right-hand diagram. Different CFSE concentrations were used to distinguish between the various peptide-loaded populations, while a control population without peptide was labeled with chloromethyl-benzoyl-aminotetramethyl-rhodamine (CMTMR) alone. Representative FACS profiles for each treatment group are shown. Antigen-specific lysis was calculated at 16 hours after target cell administration, with percent specific lysis calculated as the mean proportion of antigen-loaded cells lysed relative to that of control populations without antigen. (C) Growth of s.c. implanted E.G7-OVA tumors was assessed in animals treated therapeutically with a combination of OVA protein and $\alpha$-GalCer, by the i.v. or oral route, or with oral OVA and vehicle, 5 days after tumor challenge. to NY-ESO-1 157-165 (v) peptide (amino acids 157-164 of NY-ESO-1 with substituted valine at position 165) were significantly enhanced by coadministration of $\alpha$-GalCer (Figure 5C). Only responses primed in the presence of $\alpha$-GalCer could be effectively restimulated by injection of vacc-NY-ESO-1 (Figure 5D). Enzyme-linked immunospot analysis after restimulation in a repeated experiment indicated that there were significantly enhanced numbers of IFN- $\gamma$-secreting cells in the spleens of $\alpha$-GalCertreated animals (data not shown). Thus, this prime-boost strategy can be used to induce effector cells with specificity for a promising tumor target at potentially therapeutic levels.

Oraladministration of antigen together with $\alpha$-GalCer induces functional CTLs. Murine $i$ NKT cells are found in relative abundance in bone marrow, thymus, spleen, and liver, while they are present in low numbers in the blood and peripheral lymph nodes (30). It is likely, therefore, that this distribution of cells will determine the efficacy of administration of $i$ NKT cell agonists by different routes. As vaccine administration via mucosal surfaces is generally seen as a preferred option in terms of likely experiment highlights the utility of $\alpha$-GalCer as an adjuvant with the potential to be used in conjunction with peptide-based, as well as protein-based, vaccines.

In order to extend this finding to a peptide of a known tumor antigen, we examined responses to a modified epitope of the CT antigen NY-ESO-1 (29) in HLA-A2-transgenic mice. In this instance, both peptide and $\alpha$-GalCer were administered by i.p injection, a route that also induces splenic DC maturation (data not shown). As was seen for the OVA epitope, responses patient usage and ease of administration, we examined the possibility of inducing immune responses by the oral route. It was first established that oral administration of $\alpha$-GalCer leads to maturation of DCs in the spleen and mesenteric lymph nodes, as defined by upregulation of CD86 on CD $11 \mathrm{c}^{+}$cells (data not shown). The Proteolytic activity in the digestive tract meant that the dose of OVA used was necessarily high, with $30 \mathrm{mg}$ administered per animal. In many reported instances, oral administration of protein at possibility of inducing CTLs by this route was then investigated. 
A
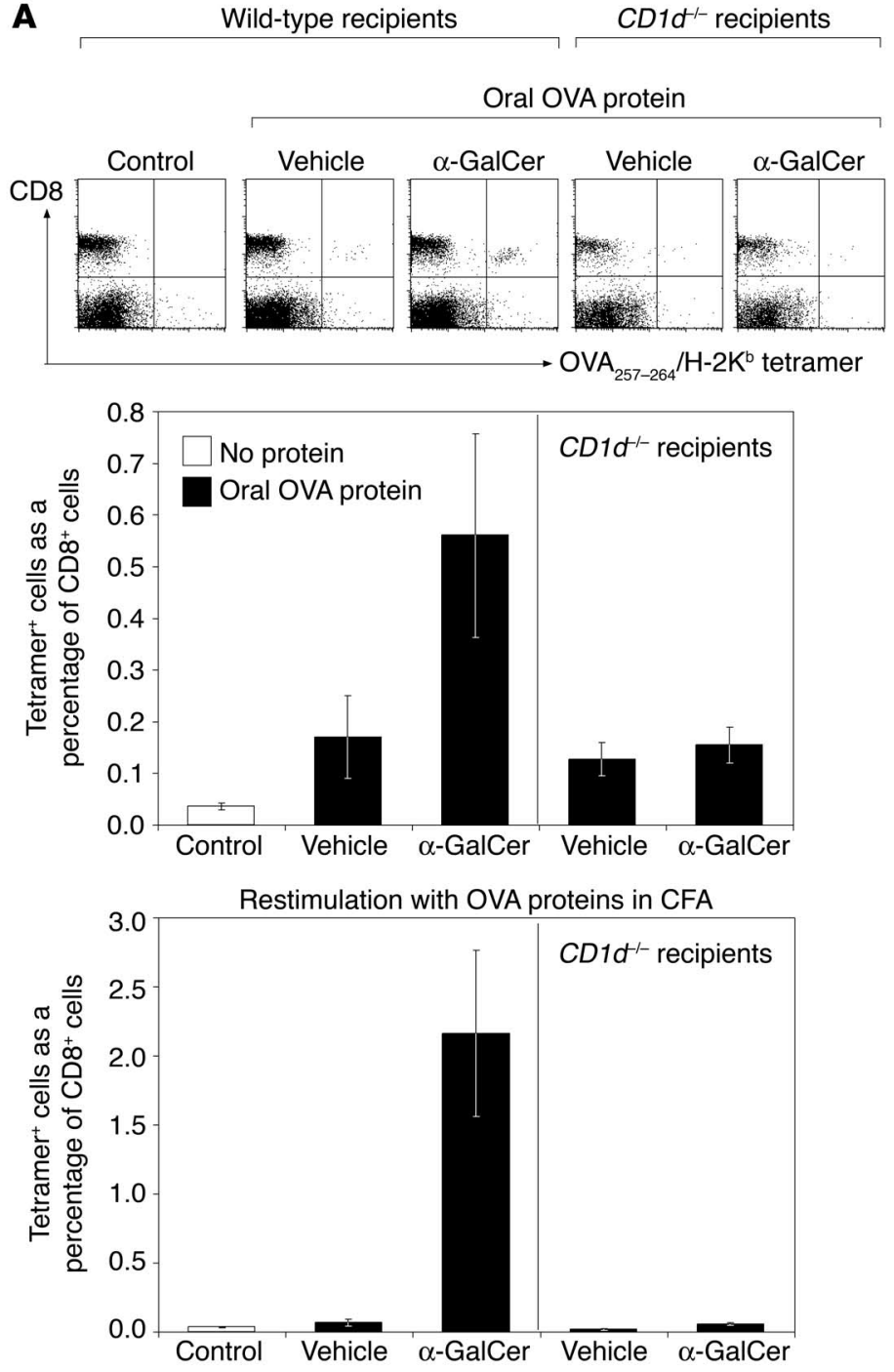

B
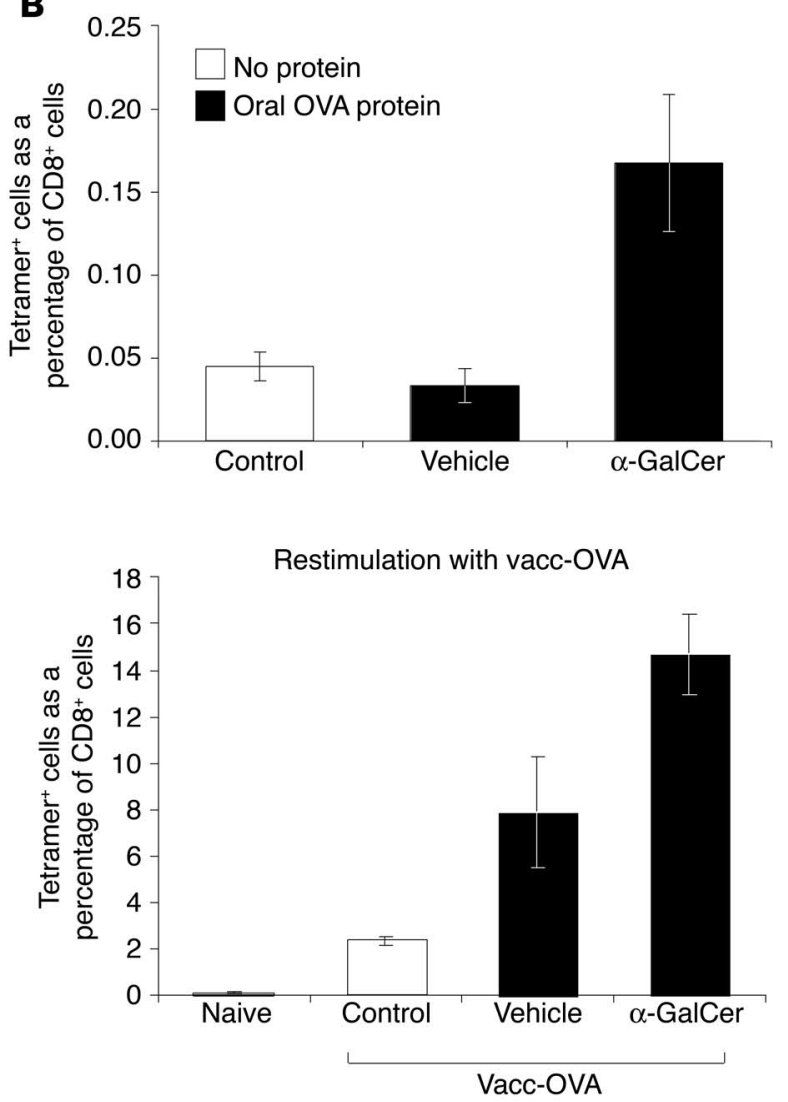

Figure 7

Oral administration of soluble antigen and $\alpha$-GalCer induces functional T cell responses with potent restimulatory capacity. (A) Whole OVA was administered by gavage to C57BL/6 or CD1 ${ }^{-1-}$ mice as in Figure 6 . Induction of OVA $257-264$ CD8 ${ }^{+}$T cell responses was assessed in the blood 7 days later (FACS profiles and top graph) and 7 days after subsequent restimulation by s.c. injection with OVA protein in CFA (lower graph). (B) $\mathrm{OVA}_{257-264}$-specific T cell responses were induced in C57BL/6 mice by oral administration of OVA as in Figure 6 (top panel) and were subsequently restimulated by i.v. injection with vacc-OVA 9 days later (lower panel). Responses induced 7 days after restimulation are presented together with those observed in control animals that received vaccinia alone and those of a naive group.

this dose has led to the induction of $\mathrm{T}$ cell tolerance, rather than priming, highlighting a potential pitfall of the administration of a vaccine by this route $(31,32)$. Using tetramers to monitor immune responses in the blood 7 days after antigens were administered, we

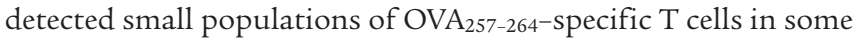
animals treated with protein in vehicle (Figure 6A). Subsequent analysis of cytotoxic capacity of the induced populations in vivo by VITAL assay, an in vivo assay of cytolytic capacity (33), indicated insignificant cytotoxic function (Figure 6B), reflecting either the small size of the induced populations or perhaps a blunted phenotype of the antigen-specific cells. In striking contrast, easily detected populations of $\mathrm{OVA}_{257-264}$-specific $T$ cells, representing an average of $0.8 \%$ of the $\mathrm{CD} 8^{+}$cell subset, were induced when protein was administered orally together with $\alpha$-GalCer. These popu- lations had cytotoxic capacity, inducing up to $60 \%$ lysis of injected targets loaded with $5 \mu \mathrm{M}$ OVA $_{257-264}$ peptide. As was found for i.v. administration, the adjuvant effect of oral $\alpha$-GalCer could be directly attributed to the activity of $i$ NKT cells, as no enhancement of $\mathrm{T}$ cell responses was observed in $C D 1 d^{-/-}$recipients, which are devoid of $i$ NKT cells (Figure 7A), or in $i$ NKT cell-deficient recipients (data not shown).

Mice receiving oral administration of OVA with $\alpha$-GalCer resisted subsequent challenge with E.G7-OVA tumors, while mice receiving oral OVA without $\alpha$-GalCer were not significantly protected (data not shown). To test the therapeutic utility of this route of vaccination, animals bearing established tumors were given a single treatment of OVA with or without $\alpha$-GalCer on day 5 after challenge, when clearly palpable tumor foci were present. As was seen with 
i.v. treatment (Figure 4), this therapy was only effective when OVA was administered together with $\alpha$-GalCer (Figure 6C). Four of the five mice treated with OVA and $\alpha$-GalCer remained tumor free after the conclusion of the experiment. Thus coadministration of $\alpha$-GalCer imparts potent anti-tumor activity to oral vaccines.

In order to investigate the restimulatory capacity of orally induced cells, we gave primed animals OVA protein in CFA by s.c. injection, which in our experiments lent a weak stimulus (Figure 7A, lower graph). Alternatively, primed animals were given an i.v. injection of vacc-OVA (Figure 7B). Interestingly, when the weaker stimulus was used, restimulation was observed only in the protein/ $\alpha$-GalCer-primed animals, with depletion of existing responses seen in the other control groups. The inability of T cells to be restimulated when protein was administered in absence of $\alpha$-GalCer may be further evidence of a blunted $T$ cell phenotype induced by oral administration, which can be effectively overcome by the adjuvant capacity of the $i$ NKT cell agonist. However, when the stronger restimulation protocol was used, specific $\mathrm{T}$ cell populations were expanded in both the protein/vehicle- and protein/ $\alpha$-GalCer-primed groups, suggesting that stimulation by viral infection can overcome defects in restimulatory capacity (34). Importantly, however, significantly larger responses were elicited in the $\alpha$-GalCer-treated animals. These data suggest that $i$ NKT cell activation has a very powerful adjuvant effect capable of eliciting effective $T$ cell responses by oral administration, a route generally considered unfavorable to stimulation of potent effector cells.

\section{Discussion}

Recent developments in biotechnology have made possible the large-scale production of recombinant proteins and peptides as clinically relevant antigenic components for preventative and therapeutic vaccines. Increasing attention is being paid to improving the efficacy of such vaccines through the use of appropriate immune adjuvants. We have reported here that administration of $i$ NKT cell ligands can greatly improve $T$ cell responses to model protein and peptide antigens, including a clinically relevant, HLA-A2-restricted epitope of the CT antigen NY-ESO-1. $\mathrm{CD}^{+} \mathrm{T}$ cell responses generated by antigen administration in the presence of $i$ NKT cell activation are cytolytic and, importantly, can be readily restimulated using recombinant viral vectors. Similarly, administration of protein antigen together with an $i$ NKT cell ligand effectively boosts previously primed responses. Adjuvants aimed at activating $i$ NKT cells may therefore be particularly suited for use in prime-boost vaccination protocols. Furthermore, the adjuvant activity of $i$ NKT cell activation was observed after oral administration of antigen, with CTLs induced by this route having therapeutic anti-tumor activity. This represents a significant step forward in the development of oral vaccines for the treatment of cancer and infectious disease.

Fujii et al. (21) have recently reported that within hours of i.v. administration of $\alpha$-GalCer, TNF- $\alpha$ and IFN- $\gamma$, released primarily by DCs, were responsible for the subsequent rapid surface remodeling of DCs, including increased expression of CD80/86 costimulatory molecules. Consistent with the provision of soluble factors resulting in the maturation of DCs, we have shown that activation of $i$ NKT cells results in trans maturation of both DCs and B cells (Figure 1B and data not shown). It has become apparent that interactions between $\mathrm{T}$ cells and DCs may involve different independent activities. Unknown trans-acting molecules released by activated CD4 T cells have also been shown to lead to upregulation of costimulatory molecules on DCs, while direct "cis" interactions, accompanied by an appropriate innate stimulus, were required for IL-12 release (22). Although data presented in Figure 1C show that CD86 expression is less pronounced in type I IFN receptor-deficient or IFN- $\gamma$ receptor-deficient mice after $\alpha$-GalCer treatment, a critical role for these IFNs could not be established with respect to $\mathrm{T}$ cell activation in vitro or vivo. Further investigation is required to establish if mediators other than TNF- $\alpha$ and IFN- $\gamma$ are involved in $i$ NKT cell-mediated adjuvant activity.

Our studies have also shown that the action of $i$ NKT cells can serve to enhance other maturation stimuli. It has been reported previously that spontaneous maturation of DC occurs upon culture of splenic tissue in vitro (26). We have shown here that the significantly upregulated expression of CD86 observed in splenic CD $11 \mathrm{c}^{+}$ cells after overnight culture was further enhanced by the presence of $\alpha$-GalCer (Figure 1B). Thus, initiation of maturation does not preclude the enhancing activity of $i$ NKT cell activation. More significantly, we have reported that DC maturation induced by a TLR ligand was also enhanced by $i \mathrm{NKT}$ cell activity (Figure 1E). Exposure of APCs to both TLR-mediated and $i$ NKT cell-mediated signals induced significantly greater $\mathrm{T}$ cell responses than exposure to either stimulus alone. These data suggest that a physiological role for $i$ NKT cells may be to amplify pathogen-derived stimuli, as has been advocated by Brigl and colleagues (28). The finding that powerful stimuli such as $\alpha$-GalCer can act in synergy with TLR ligands may be exploited in the design of vaccines. In fact, the action of $\alpha$-GalCer with MPL served to induce responses that were approximately 60 times greater than those induced by protein alone. Different combinations of $i$ NKT cell ligand and the various defined TLR ligands are currently being investigated in this context.

It has been shown that exogenous antigens can be processed and presented via the MHC class I-presenting pathway to $\mathrm{CD}^{+}$ $\mathrm{T}$ cells, a phenomenon that has been called "cross-presentation" (35-37). Although the relevance of cross-presentation is still controversial (38), the process is thought to be most efficient in subpopulations of myeloid APCs, including macrophages and DCs. Here we have reported that OVA protein was cross-presented significantly more efficiently than $\beta$-gal protein, with responses to the latter being detected only with $\alpha$-GalCer as an adjuvant, followed by boosting with vaccinia encoding $\beta$-gal (Figure 2 ). This difference may reflect intrinsic qualities of the proteins in question, such as the rate of degradation or hydrophobicity or, alternatively, may reflect differences in $\mathrm{T}$ cell precursor frequency within the host repertoire. Regardless of the differences in efficiency, the coadministration of $\alpha$-GalCer greatly improved immune responses to both proteins. This adjuvant activity was also observed with peptide-based vaccines (Figure 5), demonstrating that $i$ NKT cell activation enhances the immunostimulatory capacity of APCs. Significantly, $\mathrm{CD}^{+} \mathrm{T}$ cell responses to peptide and $\alpha$-GalCer were observed in the absence of any known $\mathrm{CD}^{+} \mathrm{T}$ cell helper function. That $i$ NKT cells can potentially substitute for $\mathrm{CD}^{+}$help has been suggested previously (39), although further investigation is required with MHC class I-restricted epitopes that are known to be exclusively helper dependent.

It should also be noted that the adjuvant effect on CTL induction, as well as anti-tumor activity, was apparent with the $\alpha$-GalCer analog $\mathrm{OCH}$ regardless of the different profile of cytokine release induced by this ligand. It may yet be possible to isolate additional $i$ NKT cell ligands with differing profiles of induced cytokine release to be used in different disease conditions. In this context, a 
"super agonist" for IFN- $\gamma$ may be useful for tumor therapy, as this cytokine can exert additional anti-tumor activity through an antiangiogenic mechanism $(40,41)$.

Effective activation of $i$ NKT cells in vivo may be dependent on the route of administration of the activating ligand. It has been observed that whereas i.v. injection of DCs loaded with $\alpha$-GalCer leads to $i$ NKT cell activation and subsequent cytokine production, s.c. administration is less effective, presumably because of a low frequency of $i$ NKT cells in the region of injection (42). We have shown here that the adjuvant effect of $\alpha$-GalCer can also be observed upon oral administration (Figures 6 and 7). Interestingly, when protein was administered by this route, and $\alpha$-GalCer was administered separately by i.v. injection, no adjuvant effect was observed (data not shown). This most likely reflects a requirement for the glycolipid and peptide antigens to be presented simultaneously, presumably on the same APC, as has been reported previously $(19,39)$. In our experiments, a single oral dose of $30 \mathrm{mg}$ OVA in the absence of $\alpha$-GalCer resulted in the induction of a small population of antigen-specific $\mathrm{CD}^{+} \mathrm{T}$ cells, which exhibited low cytotoxicity and was unable to be restimulated by subsequent exposure to whole antigen in CFA. Only when a stimulus was provided in the context of recombinant vaccinia virus was restimulation observed (Figure 7). These data suggest that oral administration of OVA results in the induction of a $\mathrm{T}$ cell population with a weak capacity for restimulation and cytolytic activity, possibly reflecting a tolerogenic process (43). Our results suggest that a strong immunogen, such as vacc-OVA, can overcome the "blunted" phenotype observed after oral administration of antigen. Significantly, when OVA was administered orally together with $\alpha$-GalCer, a population of cytotoxic $T$ cells was induced without a requirement for further viral restimulation. These cells could exert potent anti-tumor activity in a therapeutic setting (Figure 6). Although it remains unclear through what mechanism oral tolerance is induced, it is generally thought that the functional status of the APC determines the outcome of antigen exposure. Thus, $i$ NKT cells within the intraepithelial lymphocyte compartment (30) may mature resident DCs that have acquired $\alpha$-GalCer and protein. These DCs may activate $T$ cells locally or in the lamina propria, Peyer's patches, or mesenteric lymph nodes after migration. Alternatively, blood-borne dissemination of protein and $\alpha$-GalCer may result in the presentation of these antigens in the liver, where $i$ NKT cells are found in abundance. In fact, a number of studies have suggested a key role for the liver in the induction of oral tolerance. The first pass of portal blood through the liver has been shown to be required for tolerance induction, as portocaval shunts can preclude the tolerance process in animal models (44). The type of APC involved in this process has not been ascertained, although some studies have shown Kupffer cells to be required (45), while others have indicated involvement of liver sinusoidal endothelial cells (LSECs) for the induction of both $\mathrm{CD}^{+}$and $\mathrm{CD}^{+} \mathrm{T}$ cell tolerance $(46,47)$. As for the latter, it has been speculated that under normal circumstances, antigen is very efficiently acquired by LSECs and is presented in a tolerogenic fashion. In the presence of a "danger" signal, such as an adjuvant, the more conventional myeloid DCs become matured and present antigen in a stimulatory context (46). Liver $i$ NKT cells may be positioned to interact rapidly with antigen-loaded DCs, resulting in a change in functional status of the APC and the induction of a significant population of CTLs with potent cytotoxic and restimulatory capabilities.

The development of adjuvants with acceptable safety profiles may prove challenging, especially as many potential reagents, particularly TLR ligands, are the same molecules that cause fever and organ damage in disease conditions such as sepsis. It is notable that $\alpha$-GalCer has now been used in patients $(48,49)$ and was well tolerated in a dose escalation trial (49). Our results suggest that $i$ NKT cell ligands may prove to be useful therapeutic agents to be used in conjunction with peptide- or protein-based vaccination strategies aimed at eliciting immune responses against cancer and infectious diseases.

\section{Methods}

Mice and cell lines. C57BL/6 $\left(\mathrm{H}-2^{\mathrm{b}}\right)$ mice were obtained from breeding pairs originally purchased from the Jackson Laboratory. Also used were mice lacking the Ja18 TCR gene segment (50), which were devoid of V $\alpha 14$ NKT cells while having other lymphoid cell lineages intact (referred to as $i$ NKT celldeficient mice); CD1d $d^{-/-}$mice, also devoid of Va14 NKT cells (51); and the HLA-A2-transgenic strain A2 $\mathrm{K}^{\mathrm{b}}$ (52). C3H/HeJ mice, a strain with a naturally occurring mutation in the TLR4 gene, resulting in inability to respond to LPS (24), and LPS-responder controls, $\mathrm{C} 3 \mathrm{H} / \mathrm{HeN}$, were obtained from Harlan UK Limited. Also used were IFN- $\gamma$ receptor-deficient (53) and type I IFN receptor-deficient (54) mice. All mice were maintained in the Biological Services Unit at the John Radcliffe Hospital (Oxford, United Kingdom) and were used according to established institutional guidelines. Approval of care and use of animals was obtained from the Clinical Medicine Ethical Review Committee, University of Oxford, Oxford, United Kingdom. The tumor cell lines used were E.G7-OVA (55), expressing OVA protein, and Z16, which is a derivative of B16.F10 that expresses $\beta$-gal under the control of a hypoxia-responsive element from murine phosphoglycerate kinase coupled to an simian virus 40 promoter.

In vitro culture media and reagents. All cell lines were maintained in complete medium consisting of RPMI medium (Sigma-Aldrich) supplemented with $2 \mathrm{mM}$ L-glutamine, $1 \%$ penicillin/streptomycin, $50 \mu \mathrm{M}$ $\beta$-mercaptoethanol (Invitrogen), and 10\% heat-inactivated FCS (Globepharm). Chicken OVA grade VII was purchased from Sigma-Aldrich, and $\beta$-gal protein was purchased from Calbiochem. Peptides of chicken OVA $\left(\mathrm{OVA}_{257-264}\left[\mathrm{H}-2 \mathrm{~K}^{\mathrm{b}}\right.\right.$ restricted; amino acid sequence, SIINFEKL]) and $\beta$-gal ( $\beta$-gal ${ }_{96-103}\left[\mathrm{H}-2 \mathrm{~K}^{\mathrm{b}}\right.$; amino acid sequence, DAPIYTNV]) (56) were synthesized in-house or by Sigma-Genosys. The peptide NY-ESO- $1_{157-165}$ (V) (amino acid sequence, SLLMWITQV), an analog of an HLA-A2-restricted epitope from the human tumor antigen NY-ESO-1 with heightened immunogenicity (29), was obtained from Multiple Peptide Systems. The $i$ NKT cell ligand $\alpha$-GalCer (KRN7000) was supplied by Kirin Brewery Co. The analog $\mathrm{OCH}$ (27) was prepared by a strategy described previously (57). All glycolipids were solubilized in $0.5 \%$ Tween $20 /$ PBS, referred to as "vehicle." MPL extracted from Salmonella minnesota was from SigmaAldrich and was solubilized in PBS. All antibodies used for FACS analysis were obtained from BD Biosciences-Pharmingen, flow cytometry was performed on a FACScalibur (BD Biosciences), and data analysis was performed using CellQuest software (BD Biosciences).

Administration of antigens. Animals received $400 \mu \mathrm{g}$ of protein i.v., or $100 \mu \mathrm{g}$ peptide i.v. or i.p., together with $1 \mu \mathrm{g}$ of glycolipid or an equivalent volume of PBS-diluted vehicle solution ( $n=5 \mathrm{mice} /$ group). For oral administration, animals were given $30 \mathrm{mg}$ OVA and $8 \mu \mathrm{g} \alpha$-GalCer by gavage. Proteins and glycolipids were administered in PBS. OVA $257-264$ peptide was dissolved in DMSO to a concentration of $10 \mathrm{mg} / \mathrm{ml}$ and then was diluted in PBS before i.v. injection, while NY-ESO-1 157-165 (V) was injected i.p. in DMSO.

Restimulation of immune responses in vivo. Protein or peptide-induced T cell responses were boosted by i.v. injection of recombinant vaccinia virus constructs $\left(5 \times 10^{5}\right.$ to $10 \times 10^{5} \mathrm{PFU} /$ mouse $)$ encoding the full-length antigenic proteins chicken OVA, $\beta$-gal, or NY-ESO- 1 . In some cases, $\mathrm{OVA}_{257-}$ 264 -specific responses were boosted by s.c. injection with $100 \mu \mathrm{g}$ OVA protein in CFA (Sigma-Aldrich). 
Monitoring $C D 8^{+}$Tcell responses ex vivo with $M H C$ class I/peptide tetramers. Blood was obtained from the lateral tail veins of mice and then the isolated PBLs were stained directly ex vivo with tetrameric $\mathrm{H}-2 \mathrm{~K}^{\mathrm{b}} / \mathrm{OVA}_{257-264}, \mathrm{H}-2 \mathrm{~K}^{\mathrm{b}} / \beta$-gal ${ }_{96-103}$, or HLA-A2K $\mathrm{K}^{\mathrm{b}}$ NY-ESO-1 $1_{157-165(\mathrm{~V})}$ complexes as described by Palmowski et al. (6). Tetramers were prepared as described previously by Whelan et al. (58). Analysis of PBLs from naive animals revealed background staining equivalent to that observed with irrelevant peptide/MHC tetramers (data not shown).

Phenotyping of DCs from spleen. Splenocyte preparations were prepared from animals treated with $i$ NKT cell ligands by gentle "teasing" of splenic tissue through gauze in the presence of complete medium supplemented with $5 \mathrm{mM}$ EDTA. Cells expressing CD11c were enriched using anti-CD11c magnetic beads (Miltenyi Biotech) according to the manufacturer's instructions and then were assessed for the expression of maturation markers by antibody staining and flow cytometry. An antibody specific for Fc $\gamma$ RIII/II receptor (BD Biosciences Pharmingen) was used to inhibit nonspecific staining. Alternatively, expression of maturation markers was assessed on non-enriched splenocyte populations with gating on $\mathrm{CD} 11 \mathrm{c}^{+} \mathrm{CD} 45 \mathrm{R} / \mathrm{B} 220^{-}$cells. In some instances, DC maturation was assessed using splenocytes from naive animals stimulated with $\alpha$-GalCer in vitro. Splenocytes were plated at a density of $1 \times 10^{7}$ cells per well in a 24-well plate, incubated for 16 hours with $1 \mu \mathrm{g}$ $\alpha$-GalCer or an equivalent volume of vehicle solution. Expression of maturation markers was assessed by FACS as described above. Transwell assays were carried out as described in Sporri et al. (22). Briefly, cell culture inserts with a permeable membrane (0.4- $\mu \mathrm{m}$ pore size; transwell) (Falcon) were used in transwell assays. Splenocytes $\left(3.5 \times 10^{6}\right)$ from $\mathrm{C} 57 \mathrm{BL} / 6$ mice were added to the top chamber and were stimulated with $\alpha$-GalCer. Splenocytes $\left(7 \times 10^{6}\right)$ from $C D 1 d^{-/}$mice were added to the bottom chamber. After 16 hours of coculture in complete medium, the expression of CD86 molecules on DC and B cells in the transwells was analyzed by flow cytometry.

Induction of immunity with isolated splenic DCs. Cells expressing CD11c were isolated from splenic tissue using anti-CD11c magnetic beads as described above. They were then loaded with $\mathrm{OVA}_{257-264}$ peptide by incubation for 2 hours in RPMI medium supplemented with $10 \mu \mathrm{M}$ peptide, washed three times with RPMI medium, and then administered to naive recipients $\left(1 \times 10^{5}\right.$ cells/mouse) by i.v. injection. The induction of specific $\mathrm{CD}^{+} \mathrm{T}$ cell responses was monitored in the blood 7 days later using MHC class I/peptide tetramers.

In vivo cytotoxicity assay. The cytotoxic capacity of induced $\mathrm{CD}^{+} \mathrm{T}$ cell responses was measured by VITAL assay as described (33). Briefly, syngeneic splenocyte populations were loaded with $5 \mu \mathrm{M}, 500 \mathrm{nM}$, or $50 \mathrm{nM}$ target peptide, then were labeled with the fluorescent dye CFSE (Molecular
Probes) at various concentrations (1.65 nM, $0.3 \mathrm{nM}$, and $0.07 \mathrm{nM})$. A control population without antigen was labeled with $10 \mu \mathrm{M}$ chloromethylbenzoyl-aminotetramethyl-rhodamine (Molecular Probes). Equal numbers of all four populations were mixed and injected i.v. into immune mice, and specific lysis of the peptide-loaded targets was monitored by FACS analysis of blood samples. The mean percent survival of peptide-pulsed targets was calculated relative to that of the control population, and cytotoxic activity was expressed as percent specific lysis (100 minus the mean percent survival of peptide-pulsed targets).

Tumor immunity assay. Groups of C57BL/6 mice $(n=5)$ were immunized by injection of $400 \mu \mathrm{g} \beta$-gal together with $1 \mu \mathrm{g} \alpha$-GalCer, followed by injection of $5 \times 10^{5} \mathrm{PFU}$ vacc- $\beta$-gal 7 days later. One week after vaccinia treatment, these animals and unimmunized controls were challenged with $3 \times 10^{5} \mathrm{Z} 16$ tumor cells by i.v. injection. The development of lung metastases was assessed 17 days later by measurement of lung weight relative to that of untreated animals.

Anti-tumor therapy. Animals were challenged s.c. with $1 \times 10^{6}$ E.G7-OVA tumor cells, and then 4 days later, when the tumors were palpable, were treated as described in Results. Growth of the tumors was monitored every 2-3 days and the tumor size for each group was calculated as the mean of the products of bisecting diameters $( \pm S E)$. Measurements were terminated for each group when an animal within the group developed a tumor larger than $200 \mathrm{~mm}^{2}$.

\section{Acknowledgments}

The authors wish to thank the personnel of the Biomedical Services Unit of John Radcliffe Hospital for animal husbandry and Kirin Breweries for providing the $\alpha$-GalCer. Cancer Research UK (C399A2291) and the Cancer Research Institute supported this work.

Received for publication May 3, 2004, and accepted in revised form October 5, 2004.

Address correspondence to: Vincenzo Cerundolo, Tumour Immunology Unit, Weatherall Institute of Molecular Medicine, University of Oxford, John Radcliffe Hospital, Oxford OX3 9DS, United Kingdom. Phone: 44-1865-222412; Fax: 44-1865-222502; E-mail: vincenzo.cerundolo@imm.ox.ac.uk.

Jonathan D. Silk and Ian F. Hermans contributed equally to this work.
1. Boon, T., and Old, L.J. 1997. Cancer tumor antigens. Curr. Opin. Immunol. 9:681-683.

2. Jager, E., et al. 1998. Simultaneous humoral and cellular immune response against cancer-testis antigen NY-ESO-1: definition of human histocompatibility leukocyte antigen (HLA)-A2-binding peptide epitopes. J. Exp. Med. 187:265-270.

3. Ramshaw, I.A., and Ramsay, A.J. 2000. The primeboost strategy: exciting prospects for improved vaccination. Immunol. Today. 21:163-165.

4. Hanke, T., et al. 1999. Effective induction of simian immunodeficiency virus-specific cytotoxic T lymphocytes in macaques by using a multiepitope gene and DNA prime-modified vaccinia virus Ankara boost vaccination regimen. J. Virol. 73:7524-7532.

5. McConkey, S.J., et al. 2003. Enhanced T-cell immunogenicity of plasmid DNA vaccines boosted by recombinant modified vaccinia virus Ankara in humans. Nat. Med. 9:729-735.

6. Palmowski, M.J., et al. 2002. Competition between CTL narrows the immune response induced by prime-boost vaccination protocols. J. Immunol. 168:4391-4398.

7. Schneider, J., et al. 1998. Enhanced immunogenicity for $\mathrm{CD}^{+} \mathrm{T}$ cell induction and complete protective efficacy of malaria DNA vaccination by boosting with modified vaccinia virus Ankara. Nat. Med. 4:397-402.

8. Conry, R.M., et al. 2002. Safety and immunogenicity of a DNA vaccine encoding carcinoembryonic antigen and hepatitis B surface antigen in colorectal carcinoma patients. Clin. Cancer Res. 8:2782-2787.

9. Wang, R., et al. 1998. Induction of antigen-specific cytotoxic T lymphocytes in humans by a malaria DNA vaccine. Science. 282:476-480.

10. Hsu, F.J., et al. 1996. Vaccination of patients with B-cell lymphoma using autologous antigen-pulsed dendritic cells. Nat. Med. 2:52-58.

11. Celluzzi, C.M., Mayordomo, J.I., Storkus, W.J., Lotze, M.T., and Falo, L.D., Jr. 1996. Peptide-pulsed dendritic cells induce antigen-specific CTL-mediated protective tumor immunity. J. Exp. Med. 183:283-287.

12. Cerundolo, V., Hermans, I.F., and Salio, M. 2004. Dendritic cells: a journey from laboratory to clinic. Nat. Immunol. 5:7-10.

13. Medzhitov, R., and Janeway, C., Jr. 2000. The Toll receptor family and microbial recognition. Trends
Microbiol. 8:452-456.

14. Leslie, D.S., et al. 2002. CD1-mediated $\gamma / \delta \mathrm{T}$ cell maturation of dendritic cells. J. Exp. Med. 196:1575-1584.

15. Vincent, M.S., et al. 2002. CD1-dependent dendritic cell instruction. Nat. Immunol. 3:1163-1168.

16. MacDonald, H.R. 1995 . NK1.1 ${ }^{+}$T cell receptor- $\alpha / \beta^{+}$ cells: new clues to their origin, specificity, and function. J. Exp. Med. 182:633-638.

17. Lantz, O., and Bendelac, A. 1994. An invariant T cell receptor $\alpha$-chain is used by a unique subset of major histocompatibility complex class I-specific $\mathrm{CD}^{+}$and $\mathrm{CD}^{-} 8^{-} \mathrm{T}$ cells in mice and humans. J. Exp. Med. 180:1097-1106.

18. Kawano, T., et al. 1997. CD1d-restricted and TCRmediated activation of $\mathrm{V} \alpha 14 \mathrm{NKT}$ cells by glycosylceramides. Science. 278:1626-1629.

19. Hermans, I.F., et al. 2003. NKT cells enhance CD4+ and $\mathrm{CD}^{+} \mathrm{T}$ cell responses to soluble antigen in vivo through direct interaction with dendritic cells. J. Immunol. 171:5140-5147.

20. Fujii, S., Shimizu, K., Smith, C., Bonifaz, L., and Steinman, R.M. 2003. Activation of natural killer $\mathrm{T}$ cells by $\alpha$-galactosylceramide rapidly induces 
the full maturation of dendritic cells in vivo and thereby acts as an adjuvant for combined CD4 and CD8 T cell immunity to a coadministered protein. J. Exp. Med. 198:267-279.

21. Fujii, S., Liu, K., Smith, C., Bonito, A.J., and Steinman, R.M. 2004. The linkage of innate to adaptive immunity via maturing dendritic cells in vivo requires $\mathrm{CD} 40$ ligation in addition to antigen presentation and CD80/86 costimulation. J. Exp. Med. 199:1607-1618.

22. Sporri, R., and Reis e Sousa, C. 2003. Newly activated $T$ cells promote maturation of bystander dendritic cells but not IL-12 production. J. Immunol. 171:6406-6413.

23. Tomura, M., et al. 1999. A novel function of $\mathrm{V} \alpha 14^{+} \mathrm{CD} 4{ }^{+} \mathrm{NKT}$ cells: stimulation of IL-12 production by antigen-presenting cells in the innate immune system. J. Immunol. 163:93-101.

24. Poltorak, A., et al. 1998. Defective LPS signaling in $\mathrm{C} 3 \mathrm{H} / \mathrm{HeJ}$ and $\mathrm{C} 57 \mathrm{BL} / 10 \mathrm{ScCr}$ mice: mutations in Tlr4 gene. Science. 282:2085-2088.

25. Qureshi, N., Takayama, K., and Ribi, E. 1982. Purification and structural determination of nontoxic lipid A obtained from the lipopolysaccharide of Salmonella typhimurium. J. Biol. Chem. 257:11808-11815.

26. Montoya, M., et al. 2002. Type I interferons produced by dendritic cells promote their phenotypic and functional activation. Blood. 99:3263-3271.

27. Miyamoto, K., Miyake, S., and Yamamura, T. 2001. A synthetic glycolipid prevents autoimmune encephalomyelitis by inducing TH2 bias of natural killer T cells. Nature. 413:531-534.

28. Brigl, M., Bry, L., Kent, S.C., Gumperz, J.E., and Brenner, M.B. 2003. Mechanism of CD1d-restricted natural killer $\mathrm{T}$ cell activation during microbial infection. Nat. Immunol. 4:1230-1237.

29. Chen, J.L., et al. 2000. Identification of NY-ESO-1 peptide analogues capable of improved stimulation of tumor-reactive CTL. J. Immunol. 165:948-955.

30. Matsuda, J.L., et al. 2000. Tracking the response of natural killer $\mathrm{T}$ cells to a glycolipid antigen using CD1d tetramers. J. Exp. Med. 192:741-754.

31. Challacombe, S.J., and Tomasi, T.B., Jr. 1980. Systemic tolerance and secretory immunity after oral immunization. J. Exp. Med. 152:1459-1472.

32. Chen, Y., et al. 1995. Peripheral deletion of antigen-reactive $\mathrm{T}$ cells in oral tolerance. Nature. 376:177-180.

33. Hermans, I.F., et al. 2004. The VITAL assay: a ver- satile fluorometric technique for assessing CTLand NKT-mediated cytotoxicity against multiple targets in vitro and in vivo. J. Immunol. Methods. 285:25-40.

34. Yang, Y., Huang, C.T., Huang, X., and Pardoll, D.M. 2004. Persistent Toll-like receptor signals are required for reversal of regulatory $\mathrm{T}$ cell-mediated CD8 tolerance. Nat. Immunol. 5:508-515.

35. Rock, K.L., Gamble, S., and Rothstein, L. 1990. Presentation of exogenous antigen with class I major histocompatibility complex molecules. Science. 249:918-921.

36. Bevan, M.J. 1976. Cross-priming for a secondary cytotoxic response to minor $\mathrm{H}$ antigens with $\mathrm{H}-2$ congenic cells which do not cross-react in the cytotoxic assay. J. Exp. Med. 143:1283-1288.

37. Carbone, F.R., and Bevan, M.J. 1990. Class Irestricted processing and presentation of exogenous cell-associated antigen in vivo. J. Exp. Med. 171:377-387.

38. Zinkernagel, R.M. 2002. On cross-priming of MHC class I-specific CTL: rule or exception? Eur. J. Immunol. 32:2385-2392.

39. Stober, D., Jomantaite, I., Schirmbeck, R., and Reimann, J. 2003. NKT cells provide help for dendritic cell-dependent priming of MHC class I-restricted $\mathrm{CD}^{+} \mathrm{T}$ cells in vivo. J. Immunol. 170:2540-2548.

40. Ruegg, C., et al. 1998. Evidence for the involvement of endothelial cell integrin $\alpha \mathrm{V} \beta 3$ in the disruption of the tumor vasculature induced by TNF and IFN- $\gamma$. Nat. Med. 4:408-414.

41. Coughlin, C.M., et al. 1998. Tumor cell responses to IFN $\gamma$ affect tumorigenicity and response to IL-12 therapy and antiangiogenesis. Immunity. 9:25-34.

42. Fujii, S., Shimizu, K., Kronenberg, M., and Steinman, R.M. 2002. Prolonged IFN- $\gamma$-producing NKT response induced with $\alpha$-galactosylceramide-loaded DCs. Nat. Immunol. 3:867-874.

43. Strobel, S., and Mowat, A.M. 1998. Immune responses to dietary antigens: oral tolerance. Immunol. Today. 19:173-181.

44. Callery, M.P., Kamei, T., and Flye, M.W. 1989. The effect of portacaval shunt on delayed-hypersensitivity responses following antigen feeding. J. Surg. Res. 46:391-394.

45. Callery, M.P., Kamei, T., and Flye, M.W. 1989. Kupffer cell blockade inhibits induction of tolerance by the portal venous route. Transplantation. 47:1092-1094

46. Knolle, P.A., and Limmer, A. 2003. Control of immune responses by scavenger liver endothelial cells. Swiss Med. Wkly. 133:501-506.

47. Limmer, A., et al. 2000. Efficient presentation of exogenous antigen by liver endothelial cells to $\mathrm{CD}^{+} \mathrm{T}$ cells results in antigen-specific T-cell tolerance. Nat. Med. 6:1348-1354.

48. Nieda, M., et al. 2004. Therapeutic activation of $\mathrm{V} \alpha 24^{+} \mathrm{V} \beta 11^{+} \mathrm{NKT}$ cells in human subjects results in highly coordinated secondary activation of acquired and innate immunity. Blood. 103:383-389.

49. Giaccone, G., et al. 2002. A phase I study of the natural killer T-cell ligand $\alpha$-galactosylceramide (KRN7000) in patients with solid tumors. Clin. Cancer Res. 8:3702-3709.

50. Taniguchi, M., et al. 1996. Essential requirement of an invariant $\mathrm{V} \alpha 14 \mathrm{~T}$ cell antigen receptor expression in the development of natural killer T cells. Proc. Natl. Acad. Sci. U. S. A. 93:11025-11028.

51. Smiley, S.T., Kaplan, M.H., and Grusby, M.J. 1997. Immunoglobulin $\mathrm{E}$ production in the absence of interleukin-4-secreting CD1-dependent cells. Science. 275:977-979.

52. Vitiello, A., Marchesini, D., Furze, J., Sherman, L.A., and Chesnut, R.W. 1991. Analysis of the HLArestricted influenza-specific cytotoxic $\mathrm{T}$ lymphocyte response in transgenic mice carrying a chimeric human-mouse class I major histocompatibility complex. J. Exp. Med. 173:1007-1015.

53. Huang, S., et al. 1993. Immune response in mice that lack the interferon- $\gamma$ receptor. Science. 259:1742-1745.

54. Muller, U., et al. 1994. Functional role of type I and type II interferons in antiviral defense. Science. 264:1918-1921.

55. Moore, M.W., Carbone, F.R., and Bevan, M.J. 1988. Introduction of soluble protein into the class I pathway of antigen processing and presentation. Cell. 54:777-785.

56. Overwijk, W.W., Surman, D.R., Tsung, K., and Restifo, N.P. 1997. Identification of a Kb-restricted CTL epitope of $\beta$-galactosidase: potential use in development of immunization protocols for "self" antigens. Methods. 12:117-123.

57. Figueroa-Perez, S., and Schmidt, R.R. 2000. Total synthesis of $\alpha$-galactosyl cerebroside. Carbobydr. Res. 328:95-102.

58. Whelan, J.A., et al. 1999. Specificity of CTL interactions with peptide-MHC class I tetrameric complexes is temperature dependent. J. Immunol. 163:4342-4348. 